\section{References}

Gurovich, I. Ya. \& Neufeldt, A. H. (eds) (2007) Current Trends and New Service Models in Mental Healthcare. Medpractica-M. (In Russian.)

Idrissov, K. A. \& Krasnov, V. N. (2009) Mental health of the population of the Chechen Republic: a dynamic population 2002-2008 study. Zhurnal nevrologii i psikhiatrii, 109, 76-81. (In Russian.)

Koshkin, A. V. (2009) Prevalence of alcoholism in Russia in 2008. First Russian National Congress on Narcology, November 24-27. Proceedings, Moscow (ed. N. N. Ivanets), pp. 237-238. NNC Narkologii. (In Russian.) Koshkina, E. A. (2009) Substance abuses in modern Russia. First Russian National Congress on Narcology, November 24-27. Proceedings,
Moscow (ed. N. N. Ivanets), pp. 236-237. NNC Narkologii. (In Russian.)

Krasnov, V. N. (ed.) (2008) Improvement of Early Diagnostics of Mental Disorders (on the Basis of Interrelationship with Primary Care Specialists). Medpracitca-M. (In Russian.)

Krasnov, V. N. \& Gurovich, I. Y. (2007) Russian culture and psychiatry. In Culture and Mental Health (eds K. Bhui \& D. Bhugra), pp. 109-121. London: Hodder Arnold.

Nemtsov, A. V. (2009) Alcohol History of Russia: Newest Period. Librokom. (In Russian.)

Smoulevich, A. B., Syrkin, A. L., Drobijev, M. Y., et al (2005) Psychocardiology. Mental Informational Agency. (In Russian.)

\title{
Mental health in the Democratic Republic of Congo: a post-crisis country challenge
}

\section{Michel Okitapoy On'okoko, ${ }^{1,3}$ Rachel Jenkins, ${ }^{2}$ Samuel Mampunza Ma Miezi, ${ }^{3}$ Daniel Okitundu Luwa E Andjafono ${ }^{3}$ and Ildephonse Muteba Mushidi ${ }^{3}$}

\author{
${ }^{1}$ Social and Transcultural Psychiatry, McGill University, Montreal, Canada, email michel.okitapoy@mail.mcgill.ca
} 2Institute of Psychiatry, King's College London, UK ${ }^{3}$ Psychiatry Department, School of Medicine, University of Kinshasa, Democratic Republic of Congo

hep he delivery of mental healthcare in the Democratic Republic of Congo (DRC), formerly Zaire, is influenced by geography, politics, legislation and the structure of the health system, as well as traditional beliefs and culture.

The DRC is in Central Africa; the Central African Republic and Sudan border to the north, Uganda, Rwanda and Burundi to the east, Zambia and Angola to the south, and the Republic of Congo to the west; and it is separated from Tanzania by Lake Tanganyika to the east. The country occupies $2345408 \mathrm{~km}^{2}$, which is slightly greater than Spain, France, Germany, Sweden and Norway combined. For administrative purposes the country is divided into 11 provinces, each with a provincial headquarters.

The population is over 66 million, with $47 \%$ aged under 15 years and $4 \%$ over 60 . Average life expectancy at birth is 46 years for men and 49 years for women. There are around 350 ethnic groups; the largest groups are the Kongo, Luba and Mongo peoples. There are also around 600000 Pygmies, the aboriginal people of the DRC. Although some 700 local languages and dialects are spoken, there is widespread use of French (the official language); the most common local languages are Kongo, Tshiluba, Swahili and Lingala. Eighty per cent of the population are Christian, 10\% Muslim and $10 \%$ follow traditional beliefs or syncretic sects (Central Intelligence Agency, 2008).

Before independence in 1960, the DRC was under Belgian colonial rule. The economy, despite the country's vast natural resources, has greatly declined since the mid-1980s. Recent conflicts, which began in 1996, have dramatically reduced national output and government revenue and increased the external debt, as well as resulting in famine and disease and 5 million conflict-related deaths (US State Department, 2009).
Despite a current lull in overall violence, the plight of people across the eastern DRC remains dire. Thousands have been displaced following renewed violence or rumours of impending violence. Achieving mental health for the population of the DRC is a priority for its economic recovery, achievement of physical health goals and creating resilience among the local people.

\section{Mental health policy and legislation}

The DRC's mental health policy was formulated in 1999. Its essential components are advocacy, promotion, prevention, treatment, rehabilitation and education; there is also a substance misuse policy. The national mental health programme was also formulated in 1999 (World Health Organization, 2005). The Ministry of Health is responsible for the organisation, management and planning of mental health sectors, and it is represented at provincial, district and community level.

The DRC has ratified the international legal instruments concerning the rights and protection of people who are mentally ill, but there is as yet no DRC law defining the rights and protection of people with mental illness or regulating the procedures for voluntary or involuntary admission to a psychiatric hospital.

\section{Mental disorders in the DRC}

Popular beliefs persist about supernatural causes of disease in general and psychiatric problems in particular (Okitapoy, 1993; Okitapoy et al, 1996). 
Mental disorders are probably at least as common in the DRC as they are elsewhere, but there are no national epidemiological data. Statistics from two psychiatric centres, the Soins de Sante Mentale (SOSAME) Psychiatric Centre in Bukavu (a post-crisis region) and the Katwambi Centre Neuropsychopathologique (CNPP) (in Kasai province), show the following:

O $80 \%$ of patients are under the age of $40,36 \%$ aged $21-30$

O there are 1.02 female patients for each male patient

half the patients are without employment

o $6-15 \%$ of patients have schizophrenia

o $6-31 \%$ have other psychotic disorders

o $22 \%$ suffer from anxiety disorders (related to war trauma for $18 \%$, to sexual abuse for $3.5 \%$ and to other factors for the remaining $0.5 \%$ )

o $13-23 \%$ of patients have mood disorders (manic episodes, depressive disorders and bipolar disorders).

\section{Psychiatric services}

\section{Historical background}

In 1926, a psychiatric institution situated along the Congo River called Mount Stanley Lazaret was created by order of the colonial authority, and from 1928 was open to patients with mental illness, tuberculosis and leprosy. In 1960, the centre became the Mount Stanley Psychiatric Institute but in 1969 it closed. It was replaced by the CNPP-Mount Amba in 1973, associated with the University of Kinshasa medical faculty. In 1957, the CNPP opened in Katwambi.

\section{Current mental health services}

Mental healthcare is delivered by private institutions as well as general and company hospitals. According to the current national health sector plan (Ministère de la Santé, 1999), mental health should be integrated into primary care. The national mental health programme is responsible for carrying out this integration. Under the general health decentralisation policy, it is planned to establish a mental health programme in each province and district, with support for the health zones and basic health units.

However, the mental health infrastructure still remains very centralised in Kinshasa, the capital, and some provinces. There are two university institutions: the CNPP-Mont Amba in Kinshasa and the Department of Neuropsychiatry of Sendwe Hospital in Lubumbashi. There is one state hospital, operated by the Roman Catholic Brothers of Charity (the CNPP-Katwambi). In addition, there are mental health centres, $90 \%$ of which are run by Roman Catholic organisations. There are also some private clinics run by Congolese neuropsychiatrists in Kinshasa.

There are no budgetary allocations for mental health. Primary funding comes in the form of out-of-pocket expenditure by the patient or the patient's family. The cost of psychiatric treatment is considered high in relation to average earnings (World Health Organization, 2005).

\section{Mental health workforce}

Specialist human resources in mental health are also very centralised. Currently, there are 34 neuropsychiatrists for a population of over 66 million, of whom only 2 are in the provinces - the other 32 are in Kinshasa. Thirteen Congolese neuropsychiatrists are abroad (Belgium, France, Canada, the USA, and South Africa). In addition, four general practitioners have had 6 months' training in neuropsychiatry. There are 0.01 psychologist clinicians and 0.03 psychiatric nurses per 100000 population, but again they are mainly in Kinshasa. There are no occupational therapists or social workers qualified in mental health (World Health Organization, 2005, 2006).

\section{Education and training}

Medical training lasts 7 years and is available at a number of universities, including Kinshasa, Lubumbashi and Kisangani. Specialist training in neuropsychiatry for doctors and nurses is available only at the CNPP, University of Kinshasa, and lasts 5 years. That CNPP is mandated: to provide care to the community; to act as a training centre for mental health professionals at all levels, including academic and scientific personnel working in the field of neurology and psychiatry; and to serve as a biopsychosocial research centre for the University of Kinshasa.

As mental health is being integrated into primary care, regular training of primary care professionals is carried out in the field of mental health. To facilitate access to mental healthcare despite the shortage of specialists outside Kinshasa, there is a training programme of 6 months in psychiatry (at the Kinshasa CNPP) for general practitioners.

There is no training available for occupational therapy or social work.

The government also partially supports some charitable organisations like SOSAME and some non-governmental organisations that provide mental health services and training (Réseau des ONG d'Action en Santé Mentale, 2007).

\section{Human rights}

Human rights violations have been perpetrated by rebels, militiamen and other armed groups. According to Amnesty International (2007), the transitional power-sharing government since 2003 has made little progress in advancing the law and respect that are essential to securing human rights. Meanwhile, the eastern DRC partially remains under the control of some armed groups. Insecurity, unlawful killings, human rights abuses, ethnic tension, widespread rape and sexual exploitation of women and girls, torture and illegal detention, as well as the recruitment and use of child soldiers continue in many parts of the country, in some instances perpetrated by government forces. Guarantee of the safety and dignity of people returning to the country, including refugees, remains difficult (Human Rights Watch, 2007; Integrated Regional Information Networks, 2009).

\section{Conclusions}

The DRC represents a chronic emergency, with endemic poverty, conflict, violence, forced dislocation of ethnic groups, torture and rape as weapons of war, which have all had devastating effects on the population. These serious violations of international humanitarian law must be addressed to create peace, respect for human rights and dignity, equity 
and accountability. These factors need also to be taken into account in mental health policy, legislation and implementation for the well-being of the Congolese population.

The national mental health programme needs to be allocated a government budget so that it can be implemented. It will then be possible to begin to work towards mental health promotion, training in mental health for staff at all levels, epidemiological research, improvement of infrastructure, effective integration of mental health in primary care, and liaison with family, traditional and religious healers in the management of people with mental problems.

\section{References}

Amnesty International (2007) Democratic Republic of Congo. In The State of the World's Human Rights. Amnesty International. See http:// archive.amnesty.org/report2007/eng/Homepage (accessed February 2010).

Central Intelligence Agency (CIA) (2008) Democratic Republic of Congo. In World Factbook (2008). CIA.

Human Rights Watch (HRW) (2007) Report on Human Rights, Democratic Republic of Congo. HRW.
Integrated Regional Information Networks (IRIN) (2009) Democratic Republic of Congo. IRIN.

Ministère de la Santé (1999) Politique et plan directeur de développement de la santé mentale en République Démocratique du Congo. [Policy and Plan of Development for Mental Health in the Democratic Republic of Congo.] Ministère de la Santé.

Okitapoy, O. M. (1993) Communauté thérapeutique: L'expérience du Service de psychiatrie (salle 7), Hôpital Gecamines Sendwe de Lubumbashi, Zaire. [The Therapeutic Community: The Experience at the Psychiatry Service (Room 7), Hôpital Gecamines Sendwe de Lubumbashi, Zaire.] Médecine d'Afrique Noire.

Okitapoy, O. M., Malanda, S., Penge, O., et al (1996) Ethno-psychiatric approach to adultery and mental health in Kinshasa. In Psychotherapy in Africa (eds S. N. Madu, P. K. Baguma \& A. Pritz), pp. 178-182. World Council of Psychotherapy.

Réseau des ONG d'Action en Santé Mentale (ROASAM) (2007) Programme d'appui a l'intégration de la santé mentale dans les soins de santé primaires et dans les services sociaux. [Programme of Support for the Integration of Mental Health into Primary Healthcare and Social Services.] ROASAM.

US State Department (USSD) (2009) Country Reports on Human Rights. USSD.

World Health Organization (2005) Democratic Republic of Congo. In Mental Health Atlas. WHO.

World Health Organization (2006) Country Statistics Concerning the Health System of the Democratic Republic of Congo. WHO.

\title{
Community mental health provision in Pemba Island, Zanzibar: a cross-sectional survey of different stakeholder groups
}

\author{
Michel Okitapoy On'okoko, ${ }^{1}$ Ilyas Mirza² and Rachel Jenkins ${ }^{3}$
}

\begin{abstract}
'Senior Lecturer, Psychiatry Department, School of Medicine, University of Kinshasa, Democratic Republic of Congo; Former Head of Psychiatry Department, Chake-Chake Hospital, Pemba, Zanzibar, United Republic of Tanzania ${ }^{2}$ Visiting Senior Lecturer, WHO Collaborating Centre and Section for Mental Health Policy, Institute of Psychiatry, King's College London, UK, email iqmirza@gmail.com
\end{abstract} ${ }^{3}$ Professor of Epidemiology and International Mental Health Policy, Institute of Psychiatry, King's College London, UK

T -here is limited information about stakeholder perceptions of health service provision in low- and middle-income countries. We conducted a cross-sectional survey of 821 stakeholders of the community mental health services in Pemba Island, Zanzibar, Tanzania. The aim was to obtain systematic information about coverage, barriers, accountability and room for improvement as a baseline before implementation of a new mental health policy to strengthen mental health services.

Zanzibar lies off the coast of Tanzania in the Indian Ocean and consists of two main islands, Unguja (Zanzibar) and Pemba. It has served as a gateway into East Africa for traders from Arabia, Asia and Europe. Pemba has an area of approximately $900 \mathrm{~km}^{2}$ and an estimated population of 500000 (National Bureau of Statistics Tanzania, 2002).

A community mental healthcare programme was instituted for Pemba in 1994, to improve the detection and treatment of mental health disorders. However, there was no assessment of whether this was systematically established throughout the island. We therefore conducted a baseline cross-sectional survey to study the views of major stakeholders about available facilities, staffing and medication through the community mental health services in Pemba, in order to assist the further development of services and implementation of the new mental health policy.

\section{Method}

The sampling frame consisted of three groups of residents of Pemba Island:

O community leaders and members

O health workers and traditional healers

O people attending psychiatric out-patient and general medical departments, either as users presenting with mental health problems or as carers.

A questionnaire was used to collect information on: sociodemographic details; views of current provision of mental health services; explanations of the different disorders; views on treatment; views on traditional healers; and views on 